\title{
Representações sociais do Biodireito elaboradas pelos estudantes de enfermagem e direito
}

\section{Social representations of Biolaw elaborated by nursing and law students}

\section{Representaciones sociales de Bioderecho elaboradas por los estudiantes de enfermería y derecho}

\author{
Cristina Maria Miranda de Sousa', Maria Eliete Batista Moura", Maria do Socorro da Costa Feitosa \\ Alves ${ }^{\prime \prime \prime}$, Robertônio Santos Pessoa'v
}

\section{RESUMO}

Este estudo tem como objeto as Representações Sociais do Biodireito. Objetivou apreender as Representações Sociais do Biodireito e analisar como essas representações se articulam com a qualidade das ações desenvolvidas por esses estudantes de graduação em enfermagem e direito relacionadas à prevenção e ao controle das infecções hospitalares. Trata-se de pesquisa exploratória, desenvolvida na Faculdade NOVAFAPI, com 178 estudantes, que foram submetidos ao Teste de Associação Livre de Palavras e feito a Análise Fatorial de Correspondência. Os estudantes de direito, representaram o Biodireito como o direito à vida, proteção ao meio ambiente, ecossistema, ciência e ética. Os estudantes de Enfermagem representaram o Biodireito como o estudo do direito, o advogado como protetor do povo, justiça, ecologia, vida, estabilidade, dignidade, direito do cidadão a ter saúde, justiça e ética. Assim, o Biodireito foi relacionado não somente com a vida e meio ambiente, mas também com a justiça social.

Palavras chave: Direito à Saúde; Psicologia Social; Biossegurança.

\section{SUMMARY}

This study focuses on the Social Representations of the Biolaw. It was objectified to apprehend the Social Representations of Biolaw and to analyze how these representations links to the quality of the actions developed by Nursing and Law graduation students related to prevention and control of hospital cross infections. Exploratory research developed at the NOVAFAPI College, with 178 students whose had been submitted to the Free Words Association Test and made the Correspondence Factorial Analysis. The
Law' students, had represented the Biolaw as the right to the life, protection to the environment, ecosystem, science and ethics. The students of Nursing had represented the Biolaw as the study of the right, the lawyer as protective of the people, justice, ecology, life, stability, dignity, right of the citizen to have health, justice and ethics. Thus, the Biolaw was related not only with the life and environment, but also with social justice.

Key words: Right to Health; Social Psychology; Exposure to Biological Agents.

\section{RESUMEN}

Este estudio se centra en las Representaciones Sociales del Bioderecho. Objetivó comprender las Representaciones Sociales del Bioderecho y analizar cómo estas representaciones están ligadas a la calidad de las acciones desarrolladas por los estudiantes de graduación en Enfermería y Abogacía se relacionaron con la prevención y el control de infecciones cruzadas en hospitales. Es una investigación exploratoria desarrollada en la Universidad de NOVAFAPI, con 178 estudiantes sometidos a la prueba de Asociación Libre de Palabras e hizo

\footnotetext{
' Jurista. Doutoranda da Universidade Federal do Rio Grande do Norte - UFRN. Lider do Núcleo de Estudos e Pesquisas em Representações Sociais - NUEPERS, da Faculdade NOVAFAPI. cristinamiranda@novafapi.com.br

" Doutora em Enfermagem pela Escola de Enfermagem Anna Nery da Universidade Federal do Rio de Janeiro UFRJ, Profa da Graduação e do Mestrado em Enfermagem da UFPI, Coordenadora de Pesquisa e Pós-Graduação da Faculdade NOVAFAPI posgraduacao@novafapi.com.br

III Doutora em Odontologia. Professora do Doutorado da Universidade Federal do Rio Grande do Norte - UFRN alfa@ufrnet.br

IV Mestre em Direito pela USP. Doutor em Direito Público pela UFPE. Professor de Direito da FUFPI. Coordenador do Curso de Direito da NOVAFAPI. robertoniopessoa@uol.com.br
} 
la Análisis Factorial de Correspondencia. Los estudiantes de Abogacía representaron el Bioderecho como el derecho a vida, la protección al ambiente, el ecosistema, la ciencia y ética. Los estudiantes Enfermería representaron el Bioderecho como el estudio del derecho, del abogado como protector de las personas, de la justicia, de la ecología, de la vida, de la estabilidad, de la dignidad, del

\section{CONSTRUI NDO O OBJETO DE ESTUDO DAS REPRESENTAÇÕES SOCIAIS SOBRE O BIODI REI TO}

No atual momento de nossa história temse que a saúde é um dos direitos humanos mais importantes, e que sua defesa e promoção exigem o envolvimento do Estado. Neste sentido, a Constituição Federal de $1988^{(1)}$ elevou a saúde à categoria de direito fundamental, dedicando ao tema relevante atenção (artigos 196 a 200). Seu artigo 196 estabelece: “a saúde é um direito de todos e um dever do Estado, garantido mediante políticas públicas sociais e econômica que visem à redução do risco de doença e de outros agravos e ao acesso universal e igualitário às ações e serviços para sua promoção, proteção e recuperação." Este programa normativo fixado pelo Texto Constitucional deve ser concretizado através de prestações legislativas e administrativas a cargo do Estado, de tal forma a dar eficácia a este direito. Trata-se, pois, de imposições constitucionais consubstanciadas em fins e tarefas dirigidas ao Estado e à sociedade, os quais, de forma democrática, deverão conferir uma estruturação prática a este direito nas três esferas de governo (Federal, Estadual e Municipal). derecho del ciudadano de tener salud, de la justicia y de la ética. Así, el Bioderecho fue relacionado no solamente con la vida y el ambiente, pero también con la justicia social.

Palabras claves: Derecho a la Salúd; Psicología Social; Exposición a Agentes Biológicos.

Não é fácil conceituar saúde, o qual apresenta uma longa evolução histórica. A saúde das pessoas e das populações tem sido uma constante preocupação da humanidade deste os tempos mais remotos. Na Grécia antiga, saúde tem uma direta relação com exercício físico (ginástica) e dieta. O termo hygieia significa "o estado daquele que está bem na vida", apresentando um sentido claramente positivo. No futuro, com a formação da medicina e a incorporação do sentido de cura, ainda a higiene alimentar e o exercício físico são vistos como importantes meios de cura. Pode-se dizer que o estado de equilíbrio interno do homem, e dele com a organização social e a natureza, é sinônimo de saúde (2).

$\mathrm{Na}$ idade média, em razão da urbanização e do alastramento das epidemias, o conceito de saúde passa a incorporar a idéia de prevenção. No Renascimento, por sua vez, destacou-se a preocupação das cidades em prestar cuidados aos doentes pobres em seus domicílios ou em hospitais, aumentando o poder das cidades em matéria de higiene ${ }^{(3)}$. As freqüentes situações de risco a que estavam sujeitas as cidades, fez surgir a idéia de polícia médica e de vigilância sanitária.

A Organização Mundial de Saúde (OMS), em 1946, definiu saúde como "situação de 
Sousa CMM, Moura MEB, Alves MSCF, Pessoa RS. Representações sociais do Biodireito elaboradas pelos estudantes de enfermagem e direito. Revista Eletrônica de Enfermagem [serial on line] 2007 Jan-Abr; 9(1): 131-141. Available from: URL: http://www. fen.ufg. br/revista/v9/n1/v9n1a10.htm

perfeito bem-estar físico, mental e social" (4). Este conceito, a despeito de seu grande avanço, e de seu caráter positivo, foi objeto de contestações. Para muitos se tratava quase de um conceito de felicidade, e que tal estado de completo bem estar seria impossível de se alcançar, revelando-se este conceito pouco científico e operacional. Em face disso, outras conceituações foram propostas. Para Alessando Seppilli ${ }^{(5)}$, por exemplo, "saúde é a condição harmoniosa de equilíbrio funcional, físico e psíquico do indivíduo integrado dinamicamente no seu ambiente natural e social". Para John Last ${ }^{(6)}$, "saúde é um estado de equilíbrio entre o ser humano e seu ambiente, permitindo o completo funcionamento da pessoa". Já para Claude Dejour ${ }^{(7)}$, ciente de não existir um estado de completo bem estar, a saúde deveria ser entendida como a busca constante deste estado. Todos os conceitos propostos parecem acenar à necessidade de um equilíbrio interno do homem e deste com o meio ambiente.

No entanto percebe-se que a população, em geral, e até mesmo alguns estudantes e profissionais da saúde e de direito definem saúde apenas como ausência de doença. A saúde, no Brasil, é um direito do povo e dever do Estado, retratado no artigo 196 da Constituição Federal de $1988^{(1)}$, mas como garantir o direito à saúde do povo brasileiro, se o conceito de saúde é bastante complexo e envolve o direito ao completo bem estar físico, mental e social? Dessa forma, envolve também o direito à alimentação, à moradia, a proteção contra as situações que causam stress, a segurança no trabalho, o laser e também o direito de ser atendido nos serviços de saúde sem riscos de complicações por iatrogenia dos profissionais de saúde, como a aquisição de uma infecção hospitalar?

No Brasil, percebe-se que a saúdedoença, vida-morte não é tomada como um processo, como um todo, é fragmentado e limitado às intervenções estabelecidas pelas rotinas dos serviços, mais centralizada na resolução de problemas imediatos dos clientes, resultante da falta de uma visão holística e humanizada da assistência.

Os estudos, na área da saúde e do direito, pela perspectiva da Teoria das Representações Sociais (TRS) possibilita à aquisição de um conhecimento socialmente compartilhado e vinculado às construções sociais e o saber do senso comum, influenciados pelos comportamentos e atitudes dos grupos sociais. A Teoria das Representações Sociais é uma teoria sobre a construção social. A forma como a pessoa pensa o seu universo, resultam em um conhecimento socialmente construído por meio de discurso nos grupos ${ }^{(8)}$.

O conceito de Representação Social foi originado na Europa com a publicação feita por Serge Moscovici, do seu estudo sobre a representação social da psicanálise. Moscovici conceitua representações sociais: "Um sistema de valores, de noções e de práticas tendo uma dupla tendência: antes de tudo, instaurar uma ordem que permitem aos indivíduos a possibilidade de se orientar no meio ambiente social, material e de dominá-lo. Em seguida, de assegurar a comunicação entre os membros de uma comunidade, propondo-lhes um código para suas trocas e um código para nomear e classificar de maneira unívoca as partes de seu 
Sousa CMM, Moura MEB, Alves MSCF, Pessoa RS. Representações sociais do Biodireito elaboradas pelos estudantes de enfermagem e direito. Revista Eletrônica de Enfermagem [serial on line] 2007 Jan-Abr; 9(1): 131-141. Available from: URL: http://www.fen.ufg. br/revista/v9/n1/v9nla10.htm

mundo, de sua história individual ou coletiva" (9).

Representação Social é ainda definida como: “uma forma de conhecimento, socialmente elaborado e partilhado, tendo uma intenção prática e concorrendo para a construção de uma realidade comum a um conjunto social”(10). A vertente da subjetividade torna-se um eixo importante por ser o modo mais abrangente de focalizar o processo saúdedoença e os seus determinantes do contexto social.

Assim, o rompimento com o paradigma biomédico predominante apresenta-se como uma forma moderna de pensar no direito à saúde, analisando os problemas ou potenciais na dimensão interpessoal do comportamento social, considerando a influência dos contextos sociais sobre os comportamentos e suas participações na construção das próprias realidades sociais dos sujeitos/grupos.

A Teoria das Representações Sociais (TRS) por seu caráter interdisciplinar é capaz de fornecer pistas importantes à compreensão dos problemas de direito à saúde, articulando as representações sociais a diferentes comportamentos, crenças, imagens, atitudes e conhecimentos de usuários/pacientes e profissionais da saúde e do direito no atendimento das necessidades. Assim, muitos pesquisadores têm buscado nas RS, um caminho profícuo para refletirem problemas existentes na saúde, que refletem nos direitos dos pacientes, articulando a concepção psicossociológica a outras disciplinas.

A relevância da TRS na saúde se deve ao fato de ser dinâmica e visam a produção de comportamentos e interações sociais ${ }^{(8)}$.
Dessa forma as representações sociais se constituem uma "preparação para a ação" elas são dinâmicas, em face de suas capacidades para ultrapassarem os limites do domínio psicossociológico(10) .

As mesmas são definidas como um sistema de conhecimentos elaborados e compartilhados socialmente, orientando comportamentos e intervindo na definição da identidade individual, social e na construção de objetos e é a partir das RS, que o indivíduo sofre a pressão das mesmas dominantes na sociedade, e assim, nesse meio que pensa e exprime seus sentimentos ${ }^{(11)}$.

\section{Contextualização do problema}

As inquietações a respeito do tema surgiram de situações vivenciadas, como profissionais da área do Direito e da saúde, nas quais pessoas eram acometidas por infecções hospitalares com uma freqüência considerável, resultando em grande sofrimento para si mesmo e para a família. Mesmo assim, as instituições prestadoras dos serviços de saúde, pelo fato do diagnóstico da infecção hospitalar, em alguns casos, serem feito após a alta dos clientes, não se sentiam responsáveis pelo fato, ficando todos os prejuízos físicos, mentais, sociais e financeiros por conta dos clientes.

Além disso, percebia-se que, em muitos casos, esses clientes desconheciam os seus direitos e demonstravam não saber a quem recorrer, considerando que as Comissões de Controle de Infecção Hospitalar $(\mathrm{CCl} H)$ dessas instituições, além de não trabalharem com a vigilância epidemiológica das infecções 
Sousa CMM, Moura MEB, Alves MSCF, Pessoa RS. Representações sociais do Biodireito elaboradas pelos estudantes de enfermagem e direito. Revista Eletrônica de Enfermagem [serial on line] 2007 Jan-Abr; 9(1): 131-141. Available from: URL: http://www.fen.ufg. br/revista/v9/n1/v9nla10.htm

hospitalares com egressos, não se envolviam com os clientes após sua alta hospitalar.

Por outro lado, no Estado do Piauí, na área do Direito, desconhece-se a existência de profissionais especializados nos aspectos do direito sob a ótica da biologia evolucionária e nas implicações bioéticas e do biodireito relacionadas com o controle das infecções hospitalares.

Dessa forma, considerando que o Biodireito é uma disciplina importante para as novas descobertas na melhoria da condição humana e que tem como princípio: o respeito à dignidade do ser humana e aos valores fundamentais da humanidade; o acesso aos benefícios das ciências biomédicas e a proibição de tratar o corpo humano ou partes do mesmo como uma mercadoria, definiu-se como objeto de estudo, as Representações Sociais do Biodireito elaboradas por estudantes de saúde e de direito relacionado com as Infecções Hospitalares, considerando que se trata de um fenômeno complexo que não pode ser reduzido a aspectos da lógica racional, devendo ser consideradas as influências de natureza sociocultural.

O tema pela sua complexidade e amplitude, justifica-se por si só. No entanto a questão do biodireito ainda é uma novidade, que se encontra em fase inicial de discussão e compreensão por muitos dos que estudam questões relacionadas com o direito e saúde. Assim, temas centrais do biodireito como: manipulação genética, clonagem, abortamento, eutanásia e muitos outros, como ganham cada dia e cada vez mais força e espaço no mundo globalizado de hoje, onde a ciência e a tecnologia permitem com facilidade passar da ficção cientifica à realidade da experimentação e obtenção de resultados admiráveis que, por vezes, não respeitam o limite da ética, da bioética e em conseqüência do biodireito.

Dessa forma, estudos que provoquem reflexão sobre a questão, que elucidem conceitos, que possam verificar o que as pessoas sabem e percebem sobre o tema são urgentes e relevantes, além de possivelmente contribuírem para o aprimoramento do processo de formação dos profissionais da área de saúde e direito.

Poderá despertar um novo olhar para a problemática e o significado político-social do reconhecimento e do respeito à dignidade humana e o seu controle para a saúde coletiva, para os estudantes de enfermagem e direito, considerando que existem condições precárias de trabalho, ausência de cumprimento das normas, protocolos e de diagnósticos, o que não justifica que as vítimas das iatrogenias fiquem desamparadas e sem condições de buscarem os seus direitos de serem atendidos nos serviços de saúde com dignidade e sem o risco de complicações, dificultando assim, o seu retorno ao trabalho e à sua vida social.

Assim, com a apreensão e análise dessas representações sociais, pode-se intervir na definição da identidade individual, social e na produção de interações sociais desses estudantes, capazes de orientar condutas e comportamentos a partir dessas representações, considerando que o indivíduo sofre a pressão das mesmas dominantes na sociedade, e assim, nesse meio pensa e exprime seus sentimentos e realiza suas ações.

\section{OBJETIVO}


Sousa CMM, Moura MEB, Alves MSCF, Pessoa RS. Representações sociais do Biodireito elaboradas pelos estudantes de enfermagem e direito. Revista Eletrônica de Enfermagem [serial on line] 2007 Jan-Abr; 9(1): 131-141. Available from: URL: http://www. fen.ufg. br/revista/v9/n1/v9n1a10.htm

Este estudo tem o objetivo de analisar as representações sociais do biodireito elaboradas pelos estudantes dos Cursos de Graduação em Enfermagem e Direito.

\section{METODOLOGI A}

Trata-se de uma pesquisa exploratória, para analisar fenômenos sócio-culturais a partir das representações sociais acerca do biodireito, subsidiadas na Teoria das Representações Sociais. O cenário da pesquisa foi a Faculdade NOVAFAPI, localizada em Teresina(PI). A amostra foi definida a partir de um estudo piloto, partindo da concepção de saturação de idéias, preconizadas por Sá(12). Participaram desta pesquisa 178 estudantes, divididos igualmente entre os cursos de direito e enfermagem, de ambos os sexos, com idade entre 18 e 35 anos que cursavam entre o 1 o e 7ำ período, que foram submetidos ao Teste de Associação Livre de Palavras ${ }^{(13)}$, no ambiente da faculdade durante o primeiro semestre letivo de 2006.

Após a aceitação verbal dos sujeitos do estudo, foi solicitado aos mesmos que assinassem o termo de consentimento livre e esclarecido, que obedece aos preceitos éticos e legais conforme o Comitê de Ética e Pesquisa CEP/NOVAFAPI, acordado com os requisitos da Resolução 196/96 ${ }^{(14)}$, que trata das diretrizes e normas de pesquisa envolvendo seres humanos.

O Teste de Associação Livre de Palavras é uma técnica interrogativa, de aplicação rápida e de fácil compreensão amplamente utilizada nas pesquisas sobre representações sociais que permite colher elementos através de expressões verbais espontâneas menos controladas e mais autênticas, que seriam perdidas ou mascaradas nas produções discursivas ${ }^{(15)}$.

Trata-se de uma técnica que permite aos entrevistados, a partir do estímulo indutor, evocar respostas de conteúdos afetivos e cognitivo-avaliativos. Utilizou-se para este estudo a palavra indutora: biodireito.

A palavra indutora foi apresentada aos sujeitos, solicitando-lhes que associassem prontamente três palavras (ou expressões) que Ihes viesse à mente à palavras biodireito, esclarecendo que quanto menor o tempo para elaboração das respostas, maior a validação dos resultados da pesquisa. Foi também desestimulado a utilização de frases longas ou conceitos intelectualmente mais elaborados.

Os dados resultantes do teste de associação livre de palavras foram processados no software Tri-Deux Mots e interpretados por meio da Análise Fatorial de Correspondência (AFC), que consiste em destacar eixos que explicam as modalidades de respostas, mostrando estruturas constituídas de elementos do campo representacional, assim como visualizar as relações de atração e afastamento entre esses elementos a propósito de determinado objeto ${ }^{(16)}$.

O Gráfico 1, que foi gerado a partir desse processo corresponde às imagens ou campo de representação sobre o biodireito, que os sujeitos evocaram a respeito do objeto em estudo, isto é, o mapa dos agrupamentos e oposições entre os adjetivos (imagens/adjetivos) associados ao biodireito.

Para análise do material final deste processo foram consideradas as modalidades que obtiveram a contribuição por fator superior 
Sousa CMM, Moura MEB, Alves MSCF, Pessoa RS. Representações sociais do Biodireito elaboradas pelos estudantes de enfermagem e direito. Revista Eletrônica de Enfermagem [serial on line] 2007 Jan-Abr; 9(1): 131-141. Available from: URL: http://www.fen.ufg. br/revista/v9/n1/v9nla10.htm

a duas vezes a média, corresponde às modalidades ou palavras que contribuíram com maior significação na construção dos fatores. Os resultados foram interpretados segundo o referencial teórico utilizado e apresentados a seguir.

\section{RESULTADOS E DI SCUSSÃO}

Os dados produzidos a partir do teste de associação livre de palavras, enquanto instrumento de apreensão de significados do conhecimento prático, deram origem a um conjunto de 499 palavras como respostas para o estímulo indutor biodireito destas, 109 com significados diferentes, estruturadas em um espaço fatorial, através dos dois fatores (F1 e F2).

O conjunto dos dois fatores representa um percentual de contribuições de $82,2 \%$; sendo que o primeiro fator possui uma representatividade expressiva de $63,2 \%$ e o segundo com o equivalente a $19 \%$ do valor total.

No Gráfico 1, observa-se o conteúdo das representações sobre biodireito, tornando-se possível a partir da objetivação configurada no campo representacional, fazer a leitura e interpretação das modalidades de opinião pelas palavras evocadas, correlacionando-as com as variáveis fixas configuradas nos dois lados fatoriais, expresso em cores diferenciadas para facilitar a visualização das modalidades pertencentes a cada um.

Apresentam-se na cor vermelha as modalidades que compõem o fator $F 1$, na cor azul as modalidades do fator $\mathrm{F} 2$ e em verde as modalidades comuns aos dois fatores F1 e F2; em letra maiúscula as variáveis fixas que contribuíram na elaboração do campo representacional. 
Sousa CMM, Moura MEB, Alves MSCF, Pessoa RS. Representações sociais do Biodireito elaboradas pelos estudantes de enfermagem e direito. Revista Eletrônica de Enfermagem [serial on line] 2007 Jan-Abr; 9(1): 131-141. Available from: URL: http://www.fen.ufg. br/revista/v9/n1/v9nla10.htm

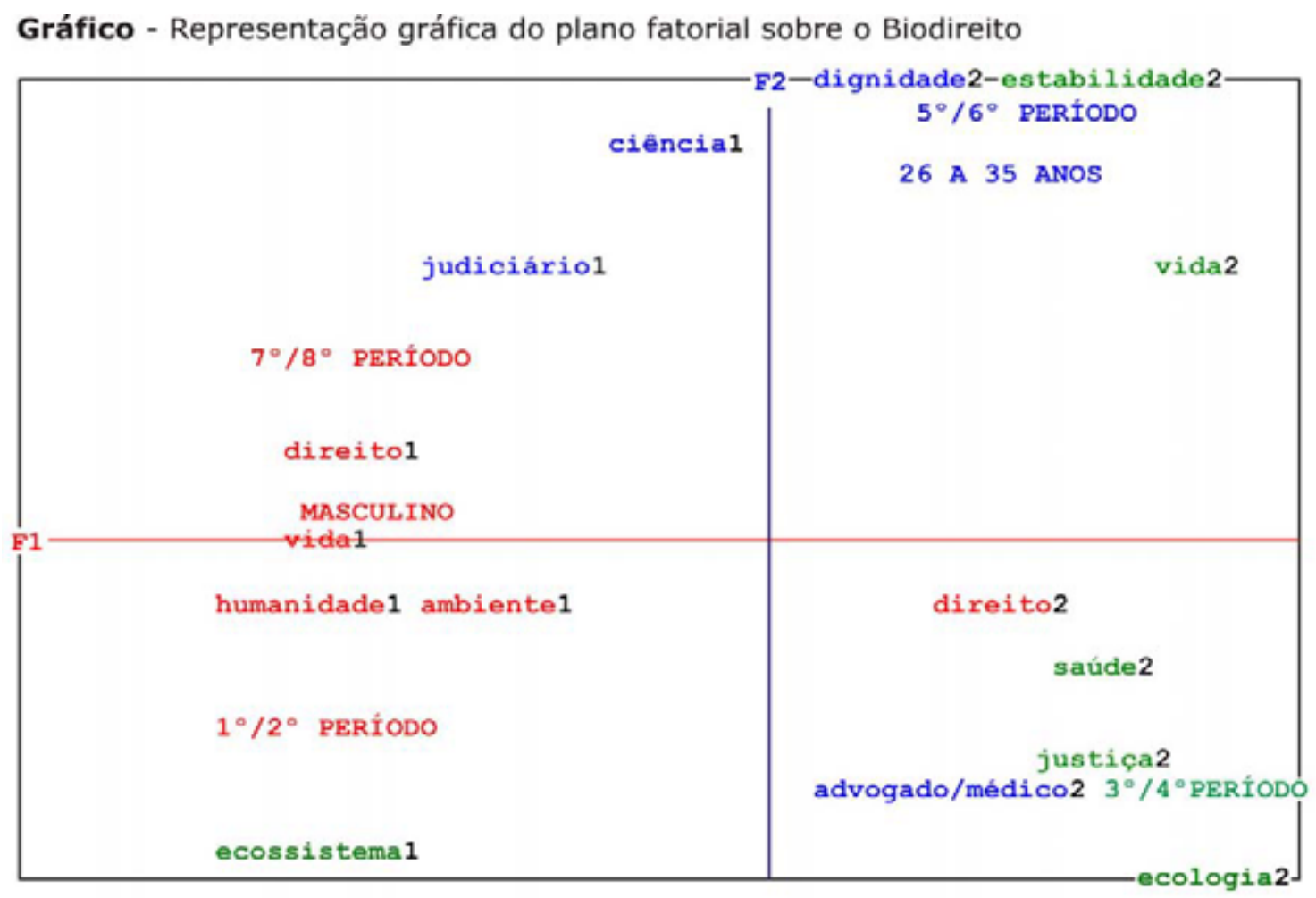

Legenda
\begin{tabular}{|l|l|l|}
\hline \multicolumn{1}{|c|}{ Plano fatorial } & \multicolumn{1}{|c|}{ Palavra indutora Biodireito } & Variáveis Fixas \\
\hline $\begin{array}{l}\text { Fator 1 (F1) }=[\text { eixo horizontal - esquerda (negativo) e } \\
\text { direita (positivo)] }\end{array}$ & $\mathbf{1}$ - Alunos de direito & 15 - Sexo \\
$\begin{array}{l}\text { Fator 2 (F2) }=[\text { eixo vertical - superior (positivo) e } \\
\text { inferior (negativo)] } \\
\text { Verde - modalidades que existem em ambos os vetores }\end{array}$ & & 16 - Idade \\
17 - Periodo & \\
\hline
\end{tabular}

No fator 1 , em vermelho campo esquerdo, encontram-se as representações sociais dos alunos de direito do sexo masculino entre os 70 e 8o período. Para estes 0 biodireito representa o direito biológico, natural, legal e à vida garantida pela justiça social, e também a proteção ao meio ambiente associado ao ecossistema, como estudo da natureza.

Dessa forma, no Direito brasileiro, a vida e a preservação do meio ambiente associada ao ecossistema, encontram proteção no artigo 5 da Constituição Federal de $1988^{1}$, que garante a inviolabilidade do direito a vida, mas além do direito a vida, despontam atualmente novos direitos, alguns deles, abordado pela jurisprudência.

Ainda no fator 1 , no campo direito, verificou-se as representações sociais dos alunos de enfermagem entre o 3 o e 4 o período. Estes consideram o biodireito o direito do cidadão a ter saúde, à vida e de existir, garantidos pela justiça e pela ética. No campo do biodireito além de abranger a vida, é estendido também ao direito à ecologia, protegendo o meio ambiente.

A problemática da responsabilidade sobre os profissionais e as instituições prestadoras de serviços de saúde traz repercussões penais, civis e éticas, as quais nascem em decorrência de atos falhos cometidos pelo profissional e acabam gerando 
Sousa CMM, Moura MEB, Alves MSCF, Pessoa RS. Representações sociais do Biodireito elaboradas pelos estudantes de enfermagem e direito. Revista Eletrônica de Enfermagem [serial on line] 2007 Jan-Abr; 9(1): 131-141. Available from: URL: http://www. fen.ufg. br/revista/v9/n1/v9n1a10.htm

conseqüências danosas a seu cliente. Muitos profissionais da área de saúde não se preocupam com os deveres éticos e jurídicos que possam the responsabilizar pelo exercício de sua profissão.

No Direito brasileiro, a vida encontra proteção no artigo 2o do Código Civil, que preceitua: "A personalidade civil do homem começa do nascimento com vida; mas a lei põe a salvo desde a concepção os direitos do nascituro." Também o art. 50 da Constituição Federal de 1988 garante a inviolabilidade do direito à vida; mas - além do direito à vida despontam atualmente novos direitos, alguns deles, abordados pela jurisprudência, por exemplo: o direito de escolher o próprio momento da morte (referido como o direito moral de morrer); o direito a não receber transfusão de sangue por motivo de convicção religiosa (caso das Testemunhas de Jeová); o direito de escolher, num laboratório, as características físicas de seu filho; o direito de não ter o filho naquele momento ou situação; o direito de não nascer com defeito genético; o direito a mudar de sexo; o direito de ter filhos geneticamente iguais. Graças às conquistas médico-biológicas, pode-se explorar, ainda, em separado, as diferentes partes do corpo humano, tais como o sangue, esperma, medula, tecidos, órgãos, como também é possível congelar embriões ou interferir no direito sucessório, modificando o parentesco através da procriação assistida ${ }^{(17)}$.

No fator 2, em azul, parte superior do campo representacional, encontram-se as representações sociais dos alunos de direito inseridos na faixa etária entre 26 a 35 anos dos 5o e 60 períodos. Este grupo ancora o biodireito em elementos valorativos associados à ciência ligados a aplicação da ética. Por outro lado os alunos de enfermagem também ancoram o biodireito na vida associada à proteção, segurança e estabilidade adquirida através da cidadania, respeito e dignidade.

Com o reconhecimento do respeito à dignidade humana, a bioética e o diodireito passam a ter um sentido humanista, estabelecendo um vínculo com a justiça. Os direitos humanos, decorrentes da condição humana e das necessidades fundamentais de toda pessoa humana, referem-se à preservação da integridade e da dignidade dos seres humanos e à plena realização de sua personalidade ${ }^{(18)}$.

Na parte inferior do fator 2, encontramse os campos semânticos das representações sociais dos alunos de direito dos 1ㅇ, 2으, 3으 e 4으 períodos. Estes alunos associam o biodireito ao ecossistema, a natureza preocupada com a flora e a fauna, preservando a terra e estudando o meio ambiente. Os alunos de enfermagem efetivam-se o biodireito com o estudo do direito, relacionado no campo jurídico, através do advogado como protetor do povo, pleiteando justiça nos tribunais amparando a assistência à saúde. Para esses alunos também foi verificado um elemento figurativo, demonstrado pela ecologia, preservando o meio ambiente.

Assim, o Direto Brasileiro, dentro do mais novo ramo específico, o biodireito, configura a responsabilidade civil dos profissionais de saúde por erro, somente quando existir a prova da sua conduta delituosa no exercício da profissão. O código Penal vigente estabelece duas situações para o 
Sousa CMM, Moura MEB, Alves MSCF, Pessoa RS. Representações sociais do Biodireito elaboradas pelos estudantes de enfermagem e direito. Revista Eletrônica de Enfermagem [serial on line] 2007 Jan-Abr; 9(1): 131-141. Available from: URL: http://www. fen.ufg. br/revista/v9/n1/v9n1a10.htm

crime; o doloso, quando o agente quis o resultado ou assumiu o risco de produzi-lo; e o culposo, quando o agente deu causa ao resultado por imprudência, negligência ou imperícia(17).

Dessa forma, com a regulamentação do Sistema único de Saúde (SUS), na Constituição de 1988 e na legislação ordinária que se seguiu (Lei $8.080 / 90$ e Lei $8.142 / 90$ ), a saúde como direito social, passou a ser a mudança fundamental preconizada pelo SUS. O conceito limitado da saúde ou à forma como os serviços estão sendo organizados, há que mudar, necessitando de uma conceituação ampla sobre a saúde, a criação de novas formas que materializem social e politicamente uma ação cuidadora integral, como direito de cidadania para os usuários do sistema de saúde no

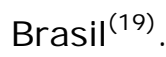

No entanto, o direito à saúde, numa perspectiva sociohistórica, deixa de ser visto somente como uma decorrência de moralidade ética ou de justiça social, e passa a ser vista de duas maneiras, como o direito à cidadania plena, no qual o direito à saúde é um valor universal, e como direito à cidadania restrita, em que o direito à saúde depende dos critérios da eficiência e racionalidade econômica. ${ }^{(20)}$.

\section{REFLEXÃO FI NAL}

Neste estudo procurou-se, analisar as representações sociais sobre 0 biodireito construídas por estudantes de enfermagem e direito, salientando os aspectos psicossociais envolvidos, determinantes ou não da adesão dos alunos à aplicação do biodireito na vida acadêmica.
Os conteúdos do conhecimento cotidiano orientam as condutas e os pensamentos dos sujeitos nas vivências diárias e as condições sociais em que vivem, as quais são responsáveis pelo modo e pela determinação do pensamento. Portanto, vale ressaltar que o fato de existir diferença entre o conhecimento científico e do senso comum, não significa dizer que este último possa não ser perfeitamente válido para seus intentos, como um meio de comunicação do conhecimento na vida cotidiana.

O conhecimento cotidiano permite ao indivíduo interiorizar as práticas sociais, as experiências e os comportamentos, utilizandose de um sistema de interpretação veiculado às formas de comunicação social, através das quais os indivíduos constroem e se apropriam de objetos sociais.

O biodireito como objeto social, constituiu o foco deste estudo, a partir do qual os estudantes de enfermagem e direito puderam explicitar as representações sociais através do instrumento de pesquisa, o Teste de Associação Livre de Palavras, que possibilitou diferentes formas de apreensão de representações sociais.

Os resultados indicaram que os conteúdos apreendidos da análise mostram os núcleos de significados sobre o biodireito ancorados nas dimensões psicossociais e culturais evidenciando também aspectos sóciohistóricos. Dessa forma, as práticas presentes no grupo social são sustentadas por razões históricas e culturais, socialmente instituídas, apresentando de forma velada determinantes normativas e com valores institucionais. 
Sousa CMM, Moura MEB, Alves MSCF, Pessoa RS. Representações sociais do Biodireito elaboradas pelos estudantes de enfermagem e direito. Revista Eletrônica de Enfermagem [serial on line] 2007 Jan-Abr; 9(1): 131-141. Available from: URL: http://www. fen.ufg. br/revista/v9/n1/v9n1a10.htm

A partir das evocações, percebe-se que os estudantes falam de elementos do biodireito ancoradas em representações sociais relacionadas não somente com a vida e meio ambiente, mas também com a questão da justiça social.

Neste sentido, muitos pesquisadores têm buscado nas representações sociais um campo rico para refletirem fenômenos/objetos conflituosos na área da saúde, no que concerne aos direitos do paciente com ênfase nos aspectos psicossociológico articulado a outras disciplinas e profissionais.

Observou-se então, a importância da utilização da referida teoria no biodireito para estudos e pesquisas capaz de revelar o pensamento humano em contextos singulares da saúde, tendo como produto um conhecimento socialmente construído e compartilhado.

\section{REFERÊNCI AS}

1. Brasil. Constituição Federal. Brasília (DF): Congresso Nacional; 1988.

2. Platão. A República. S. Paulo: Martins Fontes, 2004.

3. Rauch A. Histoire de la santé. Paris (FR): PUF, 1995.

4. Ferraz MSFC. O conceito de Saúde. Revista de Saúde Pública 1997 31(5): 538-42.

5. Berlinger G. A doença. S. Paulo: CebesHucitec, 1998.

6. Last JM. Health - A dictionary of epidemiology. New York (USA): Oxford University Press, 1983.

7. Dejours, C. Por um novo conceito de saúde. Revista Brasileira de Saúde Ocupacional, 1986 14(54), 7-11.

8. Wagner W. Sócio-gênese e características das Representações Sociais. In: Antonia SPM, Denize CO. Estudos Interdisciplinares de Representações Sociais. Goiânia $(G O)$ : AB ; 2000.

9. Moscovici S. A Representação Social da Psicanálise. Rio de Janeiro (RJ): Zahar; 1978.
10. Jodelet D. Représentations sociales: un domaine en expansion. In Jodelet D (Org). Les Représentations sociales. Paris: PUF, 1997. p. 47-78.

11. Jodelet D. As Representações Sociais. Rio de J aneiro (RJ): UERJ ; 2001.

12. Sá CP. Núcleo Central das Representações Sociais. Petrópolis (RJ): Vozes; 1996.

13. De Rosa AS. L'association livre des mots. Roma (IT): Conexion; 1989.

14. Ministério da Saúde (BR). Diretrizes e normas regulamentadoras de pesquisa envolvendo seres humanos. Brasília (DF): Ministério da Saúde; 1996.

15. Coutinho MPL et al. Representações Sociais: Abordagem Interdisciplinar. João Pessoa (PB): Universitária UFPB; 2003.

16. Abric JC. Méthodologie de recueil des représentations socials. Paris (FR): PUF ; 1994. 17. Brasil. Código Civil. São Paulo (SP): Saraiva; 2003.

18. Diniz MH. O estado atual do biodireito, São Paulo (SP): Saraiva; 2001.

19. Puccini PT, Cecílio LCO. A humanização dos serviços e o direito à saúde. Cad. Saúde Pública 2004 Out; 20(5): 1342-1353.

20. Nogueira VMR, Pires DEP. Direito à saúde: um convite à reflexão. Cad. Saúde Pública. 2004 J un; 20(3): 753-760.

Artigo recebido em 26.12.06

Aprovado para publicação em 30.04.07 